\title{
Sellar Yolk Sac Tumor
}

National Cancer Institute

\section{Source}

National Cancer Institute. Sellar Yolk Sac Tumor. NCI Thesaurus. Code C155804.

A yolk sac tumor that arises from or adjacent to the sellar region. 